\title{
Adaptation of Skeletal Muscle Microvasculature to Increased or Decreased Blood Flow: Role of Shear Stress, Nitric Oxide and Vascular Endothelial Growth Factor
}

\author{
Olga Hudlicka ${ }^{a}$ Margaret D. Brown ${ }^{b}$ \\ a Department of Physiology, Division of Medicine, and ${ }^{\mathrm{b}}$ School of Sport and Exercise Sciences, \\ University of Birmingham, Birmingham, UK
}

\section{Key Words}

Muscle activity $\cdot$ Ischaemia $\cdot$ Angiogenesis $\cdot$ Arterioles

\begin{abstract}
This review elucidates the roles of capillary haemodynamics, nitric oxide (NO) and vascular endothelial growth factor (VEGF) in the remodelling of skeletal muscle microcirculation in response to increased (electrical stimulation) or decreased (chronic ischaemia) blood flow. During early stages of stimulation-induced angiogenesis, up-regulation of VEGF and its receptor VEGF receptor 2 is dependent on shear stress and $\mathrm{NO}$ release, whereas later, involvement of NO in the expanding capillary bed appears to be VEGF/VEGF receptor 2 independent. Arteriolar growth most likely relies on mechanical wall stresses while growth factor involvement is less clear. By contrast, in muscles with restricted blood flow, increased VEGF/VEGF receptor 2 expression after ischaemia onset is not associated with changes in shear stress or hypoxia, or capillary growth. After several weeks, VEGF protein levels are lower than normal while modest angiogenesis takes place, a temporal mismatch that limits the utility of using growth factor levels during ischaemia to assess angio-
\end{abstract}

Previous articles in this special topic series: 1. Pohl $U$, Meininger G: New Review Series in JVR: Vascular Update. J Vasc Res 2009;46:503.
(ㄷ) 2009 S. Karger AG, Basel

$1018-1172 / 09 / 0465-0504 \$ 26.00 / 0$

Fax +4161306 1234 E-Mail karger@karger.ch www.karger.com
Accessible online at:

www.karger.com/jvr genic potential. Chronic stimulation of ischaemic muscles restores their depressed endothelial-dependent arteriolar dilatation, increases capillary shear stress and VEGF receptor 2 and promotes capillary growth. In patients with peripheral vascular disease, electrical stimulation of ischaemic calf muscles increases blood flow, capillary surface area and muscle performance, offering an alternative 'endogenous' treatment to gene or cell therapy.

Copyright $\odot 2009$ S. Karger AG, Basel

\section{Introduction}

The role of mechanical forces in the growth and remodelling of vessels was described more than 100 years ago by Thoma [1], who showed the importance of velocity of blood flow and/or pressure and of surrounding tissue expansion in the growth of vasculature in the chick embryo. Later, Clark [2] and Clark and Clark [3] demonstrated the role of flow in the increase and regression of capillaries during frog larvae development and rabbit ear chamber wound healing, respectively. Despite this work, relatively little is known about the importance of mechanical forces and the mechanisms of their transduction during the growth of vessels in normal adult tissues.

Skeletal muscles are one example where vessel growth occurs under physiological circumstances in the course of exercise training. The time scale and extent of such

Tel. +44 121454 5722, E-Mail o.hudlicka@bham.ac.uk 
growth is dependent on the type of training and is related to the increase in blood flow in the active muscles. Endurance training involves oxidative muscles, increasing blood flow to this fibre type 5-6 fold and leading to associated capillary growth (15-20\% increase in capillary: fibre ratio). In contrast, with high-intensity sprint training, blood flow is increased 3-4 fold in muscles composed of white glycolytic fibres and a $20 \%$ increase in capillary supply occurs specifically in relation to these fibres, whereas these parameters are not changed in oxidative muscles in this type of training [4-7]. The onset of capillary growth is dependent on the intensity of training and is much faster in animals trained by running to exhaustion [8]. Analysis of the individual factors contributing to capillary growth during whole body exercise is complicated by the fact that there are many central cardiovascular system alterations as well as changes in water balance, acid-base status and hormonal milieu. Indeed, vascular adaptation to whole body exercise can extend well beyond the active muscle groups [9]. In contrast, activation of a specific muscle group by electrical stimulation results in a similar onset and pattern of capillary growth as with exhaustive exercise [10] but without the confounding aspects described above. Such 'involuntary' local muscle activity provides a model whereby individual mechanical factors relating to muscle contraction and blood flow and their transduction mechanisms can be studied more precisely.

Repeated muscle contractions alter the local microcirculatory haemodynamics by dilatation of arterioles leading to increases in capillary flow velocity, shear stress and, potentially, pressure. At the same time, there are spatial changes in the configuration of capillaries with the shortening and lengthening of sarcomeres during each muscle contraction. We have previously studied the effects of high muscle blood flow per se (3-fold increase after treatment with $\alpha_{1}$ receptor blocker prazosin), or stretch alone (lengthening muscle overload), or a combination of both types of mechanical stimuli (local muscle stimulation that causes contractions and doubles muscle blood flow) on the pattern of capillary growth [11] and described the involvement of metalloproteinases (MMPs) and vascular endothelial growth factor (VEGF) in capillary growth in these models [12]. In summary, capillary shear stress and wall tension are increased in muscles exposed to a longterm increase in blood flow, either by vasodilator treatment or stimulation, whereas there is no increase in blood flow [13] and a decrease in capillary flow velocity when muscles experience prolonged stretch [14].

Shear Stress, VEGF and NO in Skeletal

Muscle Microcirculation
Capillary growth in response to shear stress proceeds by division of the lumen by endothelial cell protrusion and vessel splitting, without the requirement for disturbance and breakdown of the basement membrane. MMP-2 mRNA and protein are inhibited/down-regulated by shear stress-induced nitric oxide (NO) release [15]. Stretch, on the other hand, leads to capillary growth by endothelial sprouting with increased MMP-2 expression [16], while in stimulated muscles, growth proceeds by both pathways.

Although the importance of VEGF for the maintenance of capillary supply in skeletal muscle has been demonstrated in VEGF-depleted mice [17], its expression in relation to mechanical stimuli of shear stress and/or NO in muscles exposed to long-term increases in activity has not been fully clarified. This review attempts to analyze the role of shear stress in the activation of VEGF and its receptors and/or NO in skeletal muscles with growth (training induced) or regression (restricted blood supply) of capillary and arteriolar microcirculation. It also emphasizes the role of different factors in the initiation of angiogenesis and subsequent microvascular remodelling (muscles stimulated for 2-4 or for 7 days), as well as in the early (1-3 days) and late (up to 35 days) stages of ischaemia-induced microvascular adaptations.

\section{Adaptation of the Microvascular Bed to Increased Blood Flow}

\section{Growth of Capillaries}

There is now a considerable body of evidence linking beneficial adaptation of large conduit and resistance arteries during exercise training with endothelial effects of shear stress $[9,18]$. In contrast, although capillary growth and blood flow in trained or ischaemic muscles have been studied for decades, there are few data on capillary shear stress under these conditions. It is of course known, on the basis that capillary red blood cell velocity increases significantly during acute muscle contractions [19-21], that shear stress will be elevated [22]. In muscles exposed to increased activity by stimulation for $8 \mathrm{~h} /$ day for 2 days, capillary shear stress was doubled even when muscles were at rest [23]. Also at this time, proliferation of capillary endothelial cells positive for proliferating cell nuclear antigen was raised 4.5 fold [10], but the number of capillaries was not yet increased. After a further 5 days of stimulation, shear stress and red cell velocity in individual capillaries had returned to control values since there were many more pre-capillary arterioles (density in-

J Vasc Res 2009;46:504-512 


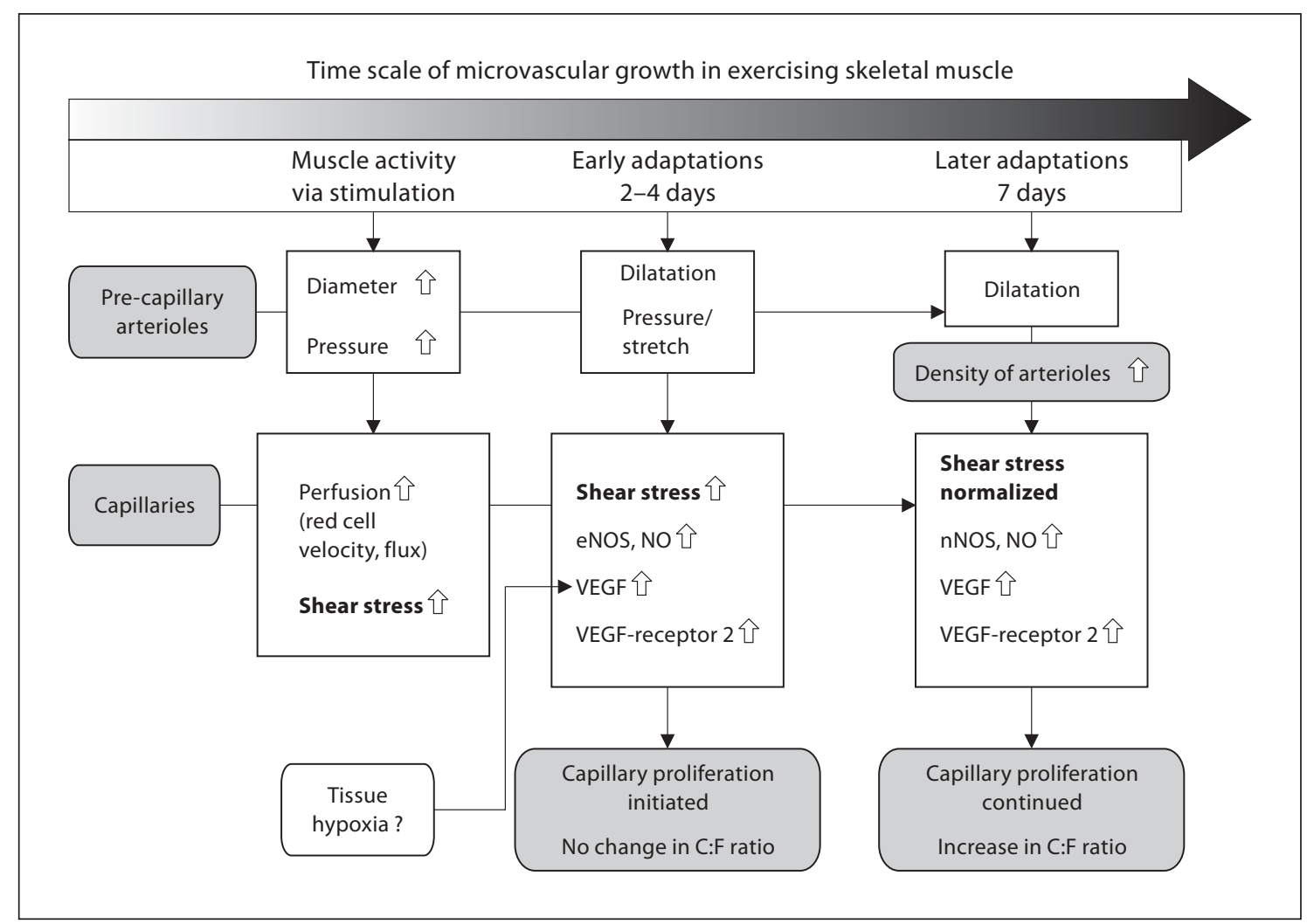

Fig. 1. Schematic representation of the time course of changes in microcirculatory haemodynamics, growth factor expression and angiogenesis during stimulation-induced muscle activity. Arrows represent increases relative to control inactive muscles. C:F ratio = Capillary:fibre ratio.

creased by $112 \%$ ) distributing flow through a capillary bed that had almost doubled in size [24].

It is known that increased shear stress in endothelial cell cultures leads to an increase in protein expression of VEGF receptor 2 (Flk-1) [25]. A similar increase was seen in skeletal muscles of mice where capillary growth was induced by long-term administration of prazosin [26] and in stimulated rat muscles, although no comparable change was found in the expression of VEGF receptor 1 (Flt-1) [27]. The time course of these changes revealed that the effect of shear stress on VEGF receptor 2 was greatest in muscles stimulated for 2 days (protein expression $2.5 \times$ control $)$ and waned at 7 days $(1.2 \times$ control $)$, demonstrating a clear association with levels of shear stress in individual capillaries. In contrast, expression of the ligand VEGF increased by $50 \%$ after 2 days of stimulation and remained elevated throughout the period of muscle activity [10]. VEGF protein is located in the subsarcolemmal region of skeletal muscle fibres and in vascular smooth muscle in addition to the capillary wall [28,
29], the latter site being the most likely to exert an effect on endothelial cell proliferation. Immunohistochemical detection of VEGF protein revealed no change in the proportion of VEGF-positive capillaries after 2 days of stimulation, but a substantial increase from $15 \%$ in control muscles to $45 \%$ in muscles stimulated for 4 and 7 days [28]. Based on these findings, a possible sequence of events in capillary growth in this model of activityinduced angiogenesis is presented schematically in figure 1.

NO is known to be released by shear stress, and its relationship to the regulation of VEGF during angiogenesis has been studied both in vitro and in vivo [30,31]. It is therefore important to evaluate the role of NO in activityinduced skeletal muscle angiogenesis. The expression of endothelial NO synthase (eNOS) protein was increased in muscles after 2 days of stimulation [10], and with longer duration, the expression of neuronal (n)NOS was elevated [32]. When eNOS and nNOS activity in stimulated muscles was inhibited by daily administration of $\mathrm{N}^{\omega_{-}}$ 
nitro-L-arginine, the increase in capillary shear stress observed after 2 days of stimulation was abolished, and shear stress was actually decreased in muscles stimulated for 7 days [23]. NOS inhibition eliminated the increased expression of VEGF and VEGF receptor 2 protein in the early stages of stimulation (2-4 days) but was without effect on their expression by the later stage (7 days). NOS inhibition also prevented capillary proliferation and the increase in capillary:fibre ratio in stimulated muscles [10]. Thus, increased capillary shear stress appears to induce the release of NO and increase VEGF and its receptor 2 expression, either directly or via NO, during the initiation of endothelial cell proliferation and angiogenesis. The later stages of capillary growth are more likely modulated by NO independently of the VEGF cascade, possibly via extracellular regulated kinases ERK-1/2 [33] or by activation of protein kinase C, ERK and c-Jun [34]. The involvement of NO in shear stress-mediated angiogenesis is also corroborated by the fact that NOS inhibition prevented capillary growth induced by increased blood flow in the chronic vasodilator treatment model, but not in muscles exposed to mechanical stretch [35] in which the initial stimulus leads to metalloproteinase activation, breakage of basement membrane and endothelial sprouting.

\section{Growth of Arterioles}

An increase in total blood flow through an exercisetrained muscle will depend not only on expansion of the capillary bed but also on growth of the pre-capillary arteriolar vessels that regulate flow through each group of capillaries [36] as well as the expansion of the upstream resistance vasculature. However, there is less information about the growth of arterioles than of capillaries in trained muscles, but it appears that, unlike capillary growth, there is no direct relationship with blood flow in the active muscles. A higher density of small arterioles has been reported after training by running, but this occurred in the rat spinotrapezius muscle that was not activated during the training exercise [37]. Moreover, endurance training in rats led to increased arteriolar density in both the white and red part of the gastrocnemius, in contrast to oxidative fibre-specific capillary growth [38], and a similar result was achieved by intensive sprint training [39]. Muscle activity induced by stimulation increased the number of pre-capillary arterioles with a similar time course to the growth of capillaries [24]. Arteriolar growth has also been reported in muscles following chronic va- sodilator treatment [40] and hypoxia [41], but it is not known whether this is directly related to blood flow and shear stress. Growth of pre-capillary arteriolar vessels is thought to occur by apposition of smooth muscle cells or pericytes to newly formed capillaries [42], and it has been suggested that the stimulus is pressure or circumferential wall stress rather than increases in shear stress [43]. Despite the importance of arterioles as flow controllers, the role of individual mechanical factors and any interaction between them [44], in determining arteriolar as opposed to capillary remodelling, is far from clear.

\section{Adaptation of the Microvascular Bed to Decreased Blood Flow}

\section{Capillary Remodelling in Ischaemia}

Changes in capillary and arteriolar supply have been studied in different animal models of ischaemia that are intended to mimic the clinical conditions of peripheral vascular disease [45]. In many cases, these involve excision of substantial arterial segments such that profound ischaemia is caused, leading to severe muscle damage, degeneration and necrosis. This is usually followed by regeneration and marked angiogenesis that is mediated by growth factors and cytokines accompanying the inflammatory state [46, 47], facilitated by dynamic regulatory systems such as angiopoietin-Tie ligand signalling [48]. Whilst this sequence of events initially replicates the condition of critical limb ischaemia, it is not representative of patients with less severe atherosclerosis who may have normal lower limb blood flow at rest but impaired functional hyperaemia. These individuals experience intermittent claudication, typically on exercise, but do not show signs of ischaemic inflammation or any significant angiogenesis $[49,50]$. The capillary:fibre ratio may even be reduced in long-standing mild-to-moderate peripheral arterial disease [51]. This latter condition is more closely mimicked by ligation of a single artery, e.g. iliac or femoral, and, in the rat, ligation promptly reduces limb blood flow both at rest and, most notably, during muscle contractions to $16 \%$ of normal. However, this is not sufficiently severe to cause necrosis and inflammation, and there is no macrophage infiltration [52] or other sign of muscle damage [53] and, moreover, no immediate capillary growth. Over the course of 2-5 weeks, the development of collateral circulation gradually restores flow to near normal levels, and it is only at this time that a remarkably modest degree of angiogenesis occurs, preceded by capillary endothelial proliferation $[27,52]$. 
From the previous section, it is evident that increased shear stress can up-regulate the expression of VEGF in capillaries. However, VEGF production is also known to be stimulated by hypoxia [54], and its enhanced expression has been observed in skeletal muscles that are severely ischaemic and undergo inflammatory regeneration [46]. As such, it has been widely viewed as a key mediator of ischaemia-induced angiogenesis in muscle [55], activated via hypoxic transcription factor HIF- $1 \alpha$ or HIF-independent transcriptional coactivator PCG-1 [56]. During the development of mild-to-moderate ischaemia in the model of iliac artery ligation, resting blood flow decreased to $30-40 \%$ of the control values after 3 days and, although it gradually increased, was still lower than in controls 5 weeks later. Blood flow during acute contractions did not increase in ischaemic muscles whereas in normally perfused muscles it increased more than 9 fold. The pattern of VEGF mRNA and protein expression was followed for up to 5 weeks after ligation, both showing a biphasic response. VEGF mRNA increased more than 7 fold during the first 3 days, returning to control level after 7 days, and increasing again to 1.5-2 times the control levels in the later stages. VEGF protein expression was elevated by $50 \%$ at the early time points, normalized after 7 days, and was actually lower than in controls at the time when proliferation and growth of capillaries occurred. Taken together, VEGF mRNA and protein expression, although elevated at the point of peak ischaemia and hypoxia, were attenuated over time, demonstrating that assessment of levels of this growth factor might not be as useful an index of angiogenic potential in response to ischaemic insult as previously thought [57].

Ischaemia by femoral artery ligation in mice also resulted in increased expression of VEGF and VEGF receptor 2 proteins, but only in a slight increase in HIF- $1 \alpha$ and in no significant changes in capillary supply in lower limb muscles. Angiogenesis occurred only when the activity of HIF- $1 \alpha$ was enhanced by an oxoglutarate analogue [58]. Thus, in mild-to-moderately ischaemic muscles, the late onset of capillary growth $[27,52]$ that is unrelated to HIF$1 \alpha$ and does not coincide with the peak increases in VEGF mRNA or protein implies that hypoxia is not the main stimulus for capillary growth in this model.

On the other hand, capillary:fibre ratio and functional hyperaemic blood flow were both significantly increased in ischaemic rat muscles by the vasodilator prazosin administered for $2-5$ weeks after ligation [59]. This suggests that restoration of blood flow and capillary shear stress in ischaemic muscles is important in the instigation of angiogenesis, a notion that is supported by the ap- pearance of capillary proliferation concurrent with the development of collateral circulation and recovery of perfusion following iliac artery ligation in the rat [52]. In order to study more clearly the roles of shear stress and growth factors in ischaemic remodelling of the microcirculation, we created a model of more consistent ischaemia by ligation of the femoral artery 3 weeks after the iliac ligation (double ligation, DL), so as to abrogate the effects of the developing collateral circulation. This resulted in greater disturbance to capillary haemodynamics, with a higher proportion of capillaries having intermittent or no red blood cell flow. In contrast to normally perfused muscles where capillary shear stress increased by $50 \%$ following muscle contractions, shear stress did not increase at all in DL muscles [60]. Intermittent electrical stimulation applied for 2 weeks to ischaemic muscles was shown previously to improve their blood flow [61], and when DL muscles were stimulated in this way, the percentage of continuously flowing capillaries became even higher than in control muscles and there were no capillaries without flow. Post-contraction capillary shear stress was 2.8 times that at rest, and it exceeded that in control muscles by $50 \%$.

Following double ligation and more persistent ischaemia, levels of VEGF protein were increased 4 fold, but there was no change in VEGF receptor 2 expression and no capillary growth. Application of intermittent stimulation to these DL muscles significantly enhanced VEGF receptor 2 expression, as in normally perfused muscles after stimulation, and, although VEGF protein levels were somewhat reduced, resulted in proliferation of capillary endothelial cells and increased capillary:fibre ratio [27]. This emphasizes yet again that up-regulation of VEGF alone is not necessarily sufficient to elicit angiogenesis, and that significant capillary growth occurs in muscles with prolonged ischaemia only in association with stimulation-induced increases in capillary shear stress and enhancement of VEGF receptor 2 expression that exceed levels in both control and ischaemic muscles (fig. 2).

\section{Arteriolar Remodelling in Ischaemia}

There is a wealth of literature concerning the development of collateral circulation in ischaemic models, much of it focusing on 'arteriogenesis', the growth and expansion of pre-existing vasculature proximal to the ischaemic territory to create a natural by-pass. Since this remodelling takes place away from the distal hypoxic tis- 


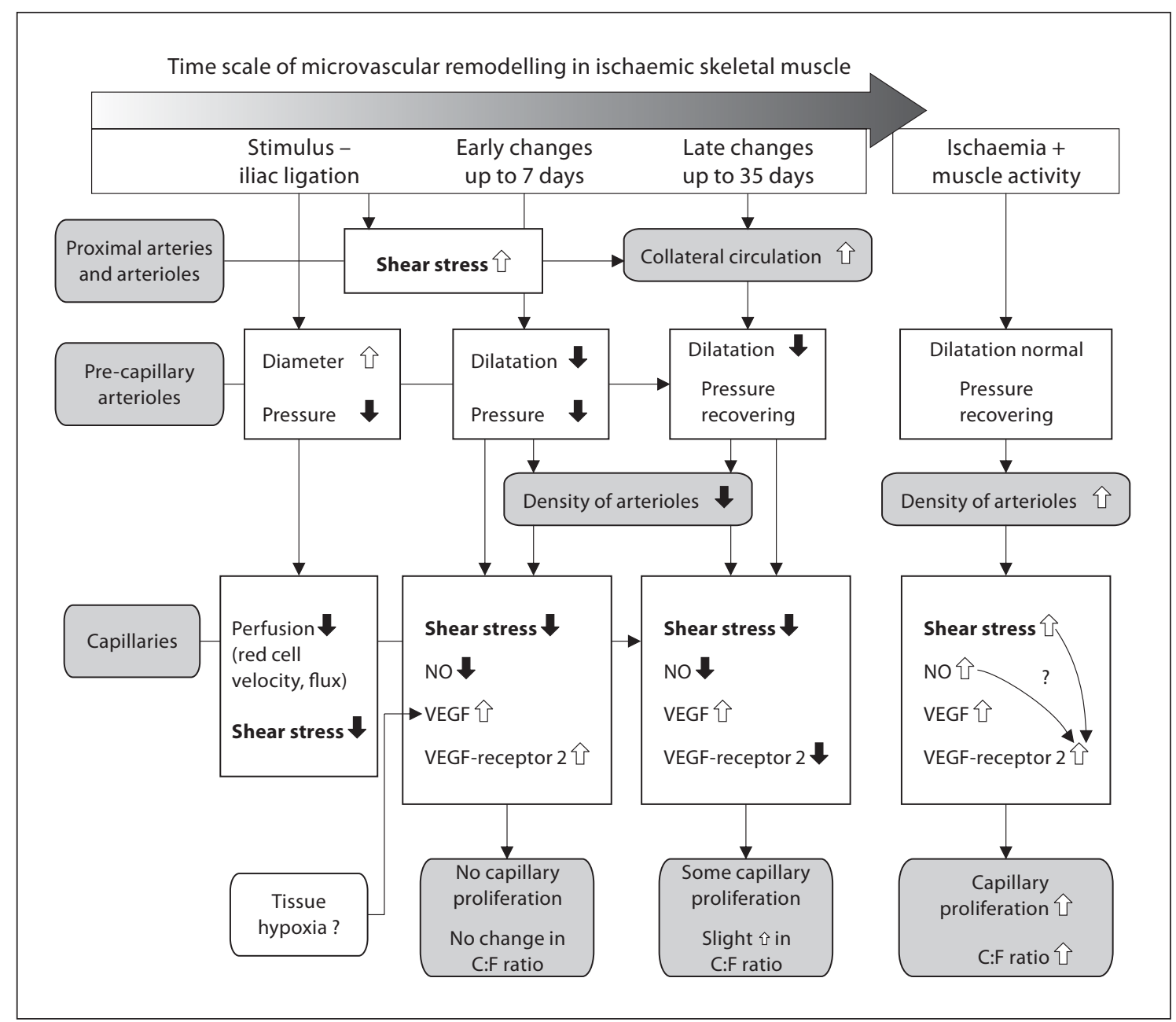

Fig. 2. Schematic representation of the time course of changes in microcirculatory haemodynamics, growth factor expression and angiogenesis during chronic mild-to-moderate muscle ischaemia induced by arterial ligation. Arrows showing changes resulting immediately after ligation and during early and late ischaemia represent alterations relative to control non-ischaemic muscles. With application of activity by stimulation to ischaemic muscles, arrows represent changes relative to both control and ischaemic muscles. C:F = Capillary:fibre ratio.

sues, Schaper and collaborators $[62,63]$ have summarized the factors stimulating arteriogenesis as the physical forces of fluid shear stress and pressure, in conjunction with cytokines and chemoattractants that aid the cell proliferation and incorporation of new elements required for vessel enlargement. In contrast, within the ischaemic muscles, impairment to red cell perfusion in capillaries is initially due to the reduced perfusion pressure, and this, over time, leads to marked changes in the reactivity of pre-capillary arterioles that exacerbate this situation. In both our models of ischaemia, iliac artery and double ligation, endothelial-dependent dilation of these flow- controlling arterioles was lost early on, with later deterioration in constrictor reactivity $[60,64]$. These functional impairments clearly impact upon capillary perfusion, and, when DL muscles received intermittent stimulation, endothelial-dependent and -independent dilation were both restored, contributing to substantial increases in capillary shear stress [60]. These effects likely involve NO because the loss of arteriolar reactivity could be mimicked by chronic NOS inhibitor treatment in normally perfused muscles and restored by stimulation [65].

Evidence concerning structural remodelling of these small arterioles during chronic ischaemia is conflicting. 
Recently, Bailey et al. [66] reported an increase in the density of small arterioles in ischaemic mouse spinotrapezius muscle without signs of muscle hypoxia, but in this small muscle, the pressure gradients following ligation would be different from our rat models where ligation is further upstream and hence more distant from the ischaemic muscles investigated. Our own studies have shown a significant reduction in $\alpha$-smooth muscle actin staining of pre-capillary arterioles $10-20 \mu \mathrm{m}$ in diameter, suggesting a loss of smooth muscle cells possibly due to the low flow and pressure condition, as well as a reduction in total eNOS protein expression [52, 65]. On the other hand, this loss of smooth muscle cells could be mimicked by NOS inhibition, which elevated perfusion pressure but impaired dilator function [65]. In both situations, i.e., ischaemia and NOS inhibition, intermittent stimulation restored arteriolar reactivity and resulted in significant increases in $\alpha$-smooth muscle actin-positive arteriolar density, suggesting that re-establishment of flow in arterioles is important for their structural integrity. As chronic stimulation also increased the expression of eNOS protein [60] and L-arginine treatment was able to restore arteriolar density in ischaemic muscles [67], NO may play a role, possibly by aiding the recruitment of mural cells [68]. In light of recent work showing either increase $[69,70]$ or no change $[71,72]$ in $\alpha$-smooth muscle staining in ischaemic muscles of patients with long-lasting peripheral arterial disease, the adaptation of arterioles to ischaemia will need much more detailed investigation.

\section{Application of Stimulation Treatment in Peripheral Arterial Disease}

It is well known that exercise training improves many symptoms in patients with peripheral vascular diseases $[73,74]$ but adherence to training programmes is often limited by co-existing cardiovascular disease, or the programme has to be adjusted to suit the limitation to exertion by the worst affected leg. Use of local muscle electrical stimulation applied to one leg at a time avoids these constraints and provides a feasible surrogate exercise alternative. When patients with intermittent claudication, limited to pain-free and maximum walking distance of about 50 and $100 \mathrm{~m}$, respectively, stimulated their calf muscles for 20 min 3 times each day for 4 weeks, their pain-free walking increased by $82 \%$ and their maximum walking by $44 \%$ [75]. Their calf muscle fatigue during isometric contraction, very much reduced by ischaemia, be- came similar to age-matched controls $[75,76]$. The microvascular benefits of stimulation were evident as a $44 \%$ increase in calf blood flow and a significant increase in capillary filtration coefficient [77].

Growth factor gene therapy and stem cell treatment are currently undergoing clinical trials as promoters of neovascularization in peripheral vascular disease but have so far yielded inconsistent results as to therapeutic effectiveness [78]. In part, this is due to difficulties in harnessing and coordinating the complexities of cellular and molecular mechanisms that lead to the addition of mature fully functional vessels particularly in critically ischaemic inflammatory conditions. Electrical stimulation offers a simple alternative means to recruit endogenous systems whereby angiogenesis can be achieved and the microvasculature of ischaemic muscle enhanced.

\section{Conclusions}

Muscle activity increased by chronic electrical stimulation leads to the enlargement of the microvascular bed, demonstrated as increased numbers of capillaries and arterioles. Capillary shear stress, increased as a result of this activity, plays an important role in activating NO, VEGF and VEGF receptor 2 in the early stages while NO, released probably by activation of nNOS, is important in the later remodelling. Shear stress due to increased capillary perfusion is also important in inducing capillary growth in ischaemic muscles, possibly by activation of VEGF receptor 2. Electrical stimulation can be used as an effective treatment in patients with peripheral vascular disease by increasing their muscle blood flow and capillary surface area.

References

1 Thoma R: Untersuchungen über die Histogenese und Histomechanik des Gefässsystems. Stuttgart, Enke Verlag, 1893.

2 Clark ER: Studies on the growth of blood vessels in the tail of frog larvae. Am J Anat 1918;23:37-88

3 Clark ER, Clark EL: Microscopic observations on the growth of blood capillaries in the living mammal. Am J Anat 1939;64:251299.

4 Armstrong RB, Laughlin MH: Blood flow within and among rat muscles as a function of time during high speed treadmill exercise. J Physiol 1983;344:189-208.

5 Armstrong RB, Laughlin MH: Exercise blood flow patterns within and among rat muscles after training. Am J Physiol 1984; 246:H59-H69. 
6 Gute D, Laughlin MH, Amann JF: Regional changes in capillary supply in skeletal muscle of interval-sprint and low-intensity endurance-trained rats. Microcirculation 1994;1:183-193.

$\checkmark 7$ Laughlin MH, Korthuis RJ, Sexton WL, Armstrong RB: Regional muscle blood flow capacity and exercise hyperemia in high-intensity trained rats. J Appl Physiol 1988;64: 2420-2427.

$\checkmark 8$ Waters RE, Rotenvatn S, Ping L, Annex BH, Yan Z: Voluntary running induces fiber type-specific angiogenesis in mouse skeletal muscle. Am J Physiol 2004;287:C1342C1348.

-9 Green DJ, Maiorana AJ, Cable NT: Exercise training does induce vascular adaptations beyond the active muscle beds. J Appl Physiol 2008;105:1002-1004.

-10 Milkiewicz M, Hudlicka O, Brown MD, Silgram H: Nitric oxide, VEGF and VEGFR-2: interactions in activity-induced angiogenesis in rat skeletal muscle. Am J Physiol 2005; 289:H336-H343.

-11 Egginton S, Zhou AL, Brown MD, Hudlicka $\mathrm{O}$ : Unorthodox angiogenesis in skeletal muscle. Cardiovasc Res 2001;49:634-646.

-12 Brown MD, Hudlicka O: Modulation of physiological angiogenesis in skeletal muscle by mechanical forces: involvement of VEGF and metalloproteinases. Angiogenesis 2003; 6:1-14.

-13 Egginton S, Hudlicka O, Brown MD, Walter $\mathrm{H}$, Weiss JB, Bate A: Capillary proliferation in overloaded rat skeletal muscle: correlation with blood flow and performance. J Appl Physiol 1998;85:2025-2032.

14 Poole D, Musch TI, Kindig CA: In vivo microvascular structural and functional consequences of muscle length changes. Am J Physiol 1997;272:H2107-H2114.

-15 Milkiewicz M, Kelland M, Colgan S, Haas T: Nitric oxide and p38 MAP kinase mediate shear stress-dependent inhibition of MMP-2 production in microvascular endothelial cells. J Cell Physiol 2006;208:229-237.

16 Rivilis I, Milkiewicz M, Boyd P, Goldstein J, Brown MD, Egginton S, Hansen FM, Hudlicka O, Haas TL: Differential involvement of MMP-2 and VEGF during muscle stretchversus shear stress-induced angiogenesis. Am J Physiol 2002;283:H1430-H1438.

-17 Tang K, Breen EC, Gerber HP, Ferrara NM, Wagner PD: Capillary regression in vascular endothelial growth factor-deficient skeletal muscle. Physiol Genomics 2004;18:63-69.

- 18 Laughlin MH, Newcomer SC, Bender SB: Importance of hemodynamic forces as signals for exercise-induced changes in endothelial cell phenotype. J Appl Physiol 2007; 104:588-600.

19 Tyml K, Cheng L: Heterogeneity of red blood cell velocity in skeletal muscle decreases with increased blood flow. Microcirculation 1995;2:181-193.
20 Anderson SI, Hudlicka O, Brown MD: Capillary red blood cell flow and activation of white blood cells in chronic muscle ischemia in the rat. Am J Physiol 1997;272:H2757$\mathrm{H} 2764$.

21 Kindig CA, Richardson TE, Poole DC: Skeletal muscle capillary hemodynamics from rest to contractions: implications for oxygen transfer. J Appl Physiol 2002;92:2513-2520.

22 Berg BR, Cohen KD, Sarelius I: Direct coupling between blood cell flow and metabolism at the capillary level in striated muscle. Am J Physiol 1997;272:H2693-H2700.

23 Hudlicka O, Brown MD, May S, Zakrzewicz A, Pries AR: Changes in capillary shear stress in skeletal muscle exposed to longterm activity: role of nitric oxide. Microcirculation 2006;13:249-259.

24 Hansen-Smith FM, Egginton S, Hudlicka O Growth of arterioles in chronically stimulated adult skeletal muscle. Microcirculation 1998;5:49-59.

25 Abumiya T, Sasaguri T, Taba Y, Mivva Y, Miyagi M: Shear stress induces expression of vascular endothelial growth factor receptor Flk-1/KDR through the CT-rich Sp1 binding site. Arterioscler Thromb Vasc Biol 2002;22: 907-913.

26 Williams JL, Weichert A, Zakrzewicz A, Da Silva-Azevedo L, Pries A, Baum O, Egginton S: Differential gene and protein expression in abluminal sprouting and intraluminal splitting forms of angiogenesis. Clin Sci 2006;110:587-595

27 Milkiewicz M, Hudlicka O, Verhaeg J, Egginton S, Brown MD: Differential expression of Flk-1 and Flk-2 in rat skeletal muscle in response to chronic ischaemia: favourable effect of muscle activity. Clin Sci 2003;105: 473-482.

-28 Milkiewicz M, Brown MD, Egginton S Hudlicka O: Shear modulation of angiogenesis and VEGF in skeletal muscles in vivo. Microcirculation 2001;8:229-241.

29 Brown MD, Milkiewicz M, Hudlicka O: Multiple sources and roles for VEGF in activity-induced angiogenesis in skeletal muscle (abstract). J Physiol 2001;536P:S279.

30 Morbidelli L, Chang CH, Douglas JG, Granger HJ, Ledda F, Ziche M: Nitric oxide mediates mitogenic effect of VEGF on coronary vascular endothelium. Am J Physiol 1996; 270:H411-H415

-31 Morbidelli L, Donnini S, Mitola D, Ziche M: Nitric oxide modulates the angiogenic phenotype of middle-T transformed endothelial cells. Int J Biochem Cell Biol 2001;33:305313.

32 Reiser PJ, Kline W, Vaghy PL: Induction of neuronal type nitric oxide synthase in skeletal muscle by chronic electrical stimulation in vivo. J Appl Physiol 1997;83:1250-1255.
33 Parenti A, Morbidelli L, Cui XL, Douglas JG, Hood JD, Granger HJ, Ledda F, Ziche M: Nitric oxide is an upstream signal of vascular endothelial growth factor-induced extracellular signal-regulated kinase 1/2 activation in postcapillary endothelium. J Biol Chem 1998;273:4220-4226.

-34 Jones MK, Tsugawa K, Tarnawski AS, Baatar $\mathrm{D}$ : Dual actions of nitric oxide on angiogenesis: possible roles of PKC, ERK and AP-1. Biochem Biophys Res Commun 2004;28: 520-528.

$>35$ Egginton S: Invited review: activity-induced angiogenesis. Pflügers Arch 2008;457:963977.

36 Segal SS: Regulation of blood flow in the microcirculation. Microcirculation 2005;12: 33-45.

37 Lash JM, Bohlen HG: Functional adaptation of rat skeletal muscle arterioles to aerobic exercise training. J Appl Physiol 1992;72:20522062.

>38 Laughlin MH, Cook JD, Tremble R, Ingram D, Colleran PN, Turk JR: Exercise training produces non-uniform increases in arteriolar density of rat soleus and gastrocnemius muscle. Microcirculation 2006:13:175-186.

>39 Binder KW, Murfee WL, Song J, Laughlin $\mathrm{MH}$, Price RJ: Computational network model prediction of hemodynamic alterations due to arteriolar remodelling in interval trained skeletal muscle. Microcirculation 2007;14:181-192.

40 Price RJ, Skalak TC: Chronic alpha-1 adrenergic block stimulates terminal and arcade arteriolar development. Am J Physiol 1996; 271:H752-H759.

41 Price RJ, Skalak TC: Arteriolar remodelling in skeletal muscle of rat exposed to chronic hypoxia. J Vasc Res 1998;35:238-244.

42 Van Gieson EJ, Murfee WL, Skalak TC, Price RJ: Enhanced smooth muscle cell coverage of microvessels exposed to increased hemodynamic stresses in vivo. Circ Res 2003;92: 929-936.

43 Price RJ, Skalak TC: Circumferential wall stress as a mechanism for arteriolar rarefaction and proliferation in a network model. Microvasc Res 1994;47:188-202.

44 Bakker EN, Versluis JP, Sipkema P, VanTeeffelen HW, Rolf TM, Spaan JA, VanBavel E: Differential structural adaptation to haemodynamics along single rat cremaster arterioles. J Physiol 2003;548:549-555.

45 Waters RE, Terjung RL, Peters KG, Annex $\mathrm{BH}$ : Preclinical models of human peripheral arterial occlusive disease: implications for investigation of therapeutic agents. J Appl Physiol 2004;97:773-780.

46 Couffinal T, Silver M, Kearney M, Witzenbichler B, Isner JM: A mouse model of angiogenesis. Am J Pathol 1998;152:1667-1679. 
-47 Madeddu P, Emanueli C, Spillman F, Meloni M, Bouby N, Richer C, Alhenc-Gelas F, Van Weel V, Eefting D, Quax PHA, Hu Y, Xu Q, Hemdahl AL, van Golde J, Huijberts M, de Lussanet Q, Struijker-Boudier H, Couffinhal T, Duplaa C, Chimenti S, Staszewsky L, Latini R, Baumans V, Levy BI: Murine models of myocardial and limb ischemia: diagnostic end-points and relevance to clinical problems. Vasc Pharmacol 2006;45:281301.

-48 Fiedler U, Augustin HG: Angiopoietins: a link between angiogenesis and inflammation. Trends Immunol 2006;27:552-558.

49 Hammarsten J, Bylund-Fellenius NC, Holm J, Schersten T, Krotkiewski M: Capillary supply and muscle fiber types in patients with intermittent claudication: relationship between morphology and metabolism. Eur J Clin Invest 1980;10:302-305.

50 Clyne CA, Mears H, Weller RO, O’Donnell TF: Calf muscle adaptation to peripheral vascular disease. Cardiovasc Res 1985;19: 507-512.

>51 Askew CD, Green S, Walker PJ, Kerr GK, Green AA, Williams AD, Febbrario MA: Skeletal muscle phenotype is associated with exercise tolerance in patients with peripheral arterial disease. J Vasc Surg 2005;41:802807.

52 Brown MD, Kent J, Kelsall CJ, Milkiewicz M, Hudlicka O: Remodelling in the microcirculation of rat skeletal muscle during chronic ischemia. Microcirculation 2003;10:179191.

-53 Anderson SI, Shiner R, Brown MD, Hudlicka O: ICAM-1 expression and leukocyte behaviour in the microcirculation of chronically ischemic rat skeletal muscle. Microvasc Res 2006;71:205-211.

54 Ferrara N: Vascular endothelial growth factor: basic science and clinical progress. Endocr Rev 2004;254:581-611.

-55 Ylä-Herttuala S, Rissanen TT, Vajanto I, Hartikainen J: Vascular endothelial growth factors: biology and current status of clinical applications in cardiovascular medicine. J Am Coll Cardiol 2007;49:1015-1026.

56 Arany Z: PGC-1 coactivators and skeletal muscle adaptations in health and disease. Curr Opin Genet Dev 2008;18:422-436
57 Milkiewicz M, Hudlicka O, Shiner R, Egginton S, Brown MD: VEGF mRNA and protein do not change in parallel during non-inflammatory skeletal muscle ischaemia in rat. J Physiol 2005;77:671-678.

58 Milkiewicz M, Pugh CW, Egginton S: Inhibition of endogenous HIF inactivation induces angiogenesis in ischaemic skeletal muscle of mice. J Physiol 2004;560:21-26.

59 Fulgenzi G, Graciotti L, Collis MG, Hudlicka O: The effect of alphal adrenoceptor agonist prazosin on capillary supply, blood flow and performance in a rat model of chronic muscle ischaemia. Eur J Vasc Endovasc Surg 1998;16:71-77.

60 Brown MD, Kelsall CJ, Milkiewicz M, Anderson S, Hudlicka O: A new model of peripheral arterial disease: sustained impairment of nutritive microcirculation and its recovery by chronic electrical stimulation. Microcirculation 2005;12:373-381.

61 Hudlicka O, Brown MD, Egginton S, Dawson JM: Effect of long-term electrical stimulation on vascular supply and fatigue in chronically ischemic muscles. J Appl Physiol 1994;77:1317-1324.

62 Heil M, Eitenmueller I, Schmitz-Rixen T, Schaper W: Arteriogenesis versus angiogenesis: similarities and differences. J Cell Mol Med 2006;10:45-55.

63 Schaper W: Collateral circulation: past and present. Basic Res Cardiol 2009;104:5-21.

64 Kelsall CJ, Brown MD, Hudlicka O: Alterations of small arterioles in rat skeletal muscles as a result of chronic ischaemia. J Vasc Res 2001;38:212-218.

65 Kelsall CJ, Brown MD, Kent J, Kloehn M, Hudlicka O: Arteriolar endothelial dysfunction is restored in ischaemic muscles by chronic electrical stimulation. J Vasc Res 2004;41:241-251.

66 Bailey AM, O’Neil TH, Morris CE, Peirce SM: Arteriolar remodelling following ischemic injury extends from capillary to large arteriole in the microcirculation. Microcirculation 2008;15:389-404.

67 Kelsall CJ, Brown MD, Kent J, Hudlicka O: $\mathrm{L}$-arginine supplementation enhances bradykinin but not ACh-dependent dilation of resistance arterioles in ischemic skeletal muscles (abstract). FASEB J 2000;14:A14.

68 Yu J, deMuinck ED, Zhuang Z, Drinane M, Kauser K, Rubanyi GM, Qian HS, Murata T, Escalante B, Sessa WC: Endothelial nitric oxide synthase is critical for ischemic remodelling, mural cell recruitment, and blood flow reserve. Proc Natl Acad Sci USA 2005;102:10999-11004.
69 Baum O, Djonov V, Ganster M, Widmer M, Baumgartner I: Arteriolization of capillaries and FGF-2 upregulation in skeletal muscles of patients with chronic peripheral arterial disease. Microcirculation 2005;12:527-537.

70 Baum O, Ganster M, Baumgartner I, Nieselt $\mathrm{K}$, Djonov V: Basement membrane remodeling in skeletal muscles of patients with limb ischemia involves regulation of matrix metalloproteinases and tissue inhibitor of matrix metalloproteinases. J Vasc Res 2007;44: 202-213.

71 Ho TK, Rajkumar V, Ponticos M, Leoni P, Black DC, Abraham DJ, Baker DM: Increased endogenous angiogenic response and hypoxia-inducible-factor-1 alpha in human critical limb ischaemia. J Vasc Surg 2006;43:125-133.

72 Ho TK, Rajkumar V, Black CM, Abraham DJ, Baker DM: Increased angiogenic response but deficient arteriolization and abnormal microvessel ultrastructure in critical leg ischaemia. Br J Surg 2006;93:1368-1376.

73 Tan KH, Cossart L, Edwards PR: Exercise training and peripheral vascular disease. $\mathrm{Br}$ J Surg 2000;87:553-562.

74 Gardner AW, Poehlman ET: Exercise rehabilitation programs for the treatment of claudication pain. A meta-analysis. JAMA 1995; 274:975-980.

75 Anderson SI, Whatling P, Hudlicka O, Gosling P, Simms M, Brown MD: Chronic transcutaneous electrical stimulation of calf muscles improves functional capacity without inducing systemic inflammation in claudicants. Eur J Vasc Endovasc Surg 2004;27: 201-209.

76 Tsang GM, Green MA, Crow AJ, Smith FC, Beck S, Hudlicka O, Shearman CP: Chronic muscle stimulation improves ischaemic muscle performance in patients with peripheral vascular disease. Eur J Vasc Surg 1994;8: 419-422.

77 Oldfield MA, Simms M, Brown MD: Microvascular filtration capacity is modified by chronic muscle stimulation in ischemic human limbs without changes in local vascular control (abstract). Microcirculation 2005;12: 666 .

78 Kalka C, Baumgartner K: Gene and stem cell therapy in peripheral arterial occlusive disease. Vasc Med 2008;13:157-172. 